\title{
Profile of Students' Cognitive Ability in Chemistry Learning using Chemistry Systemic Multiple Choice Questions (CSMCQs)
}

\author{
${ }^{1}$ Metridewi Primastuti, ${ }^{2}$ Erfan Priyambodo \\ ${ }^{1}$ Chemistry Education Program; Graduate School; Yogyakarta State University; \\ Yogyakarta 55281, Indonesia \\ ${ }^{2}$ Department of Chemistry Education; Faculty of Mathematics and Natural Science; \\ Yogyakarta State University; Yogyakarta 55281, Indonesia \\ Corresponding author: metridewi.me@gmail.com
}

\begin{abstract}
The systemic approaches connect a set of interacting, functioning, and interdependent or elements with mutual relationships. The objective of this study is to analyze how students' cognitive ability profiles if measured using Chemistry Systemic Multiple Choices Questions (CSMCQs). This study was conducted by testing CSMCQs to the 157 students who studied with the usual learning approaches by teachers. Data collection technique were conducted using the objective test instruments consist of $\mathrm{C}_{1}$ to $\mathrm{C}_{6}$ cognitive abilitiy domains. Data were analyzed using descriptive percentage analysis. The results showed that students' cognitive ability is in the highest category. Based on these result, Chemistry Systemic Multiple Choice Questions (CSMCQs) can be used as an alternative learning evaluation instrument to develop students' cognitive abilities.
\end{abstract}

Keywords: Chemistry Education, CSMCQs, Students' Cognitive Ability.

\section{INTRODUCTION}

The objective of education is to develop memory and conduct the transfer of science. The indicator of the success of teaching and learning process is the ability of students to use what has been learned in the classroom to answer the given problem [1]. Research on science learning achievement has focused on cognitive abilities factors as determinants of learning and achievement. Snow's (1989) give an idea of pathway to learning outcomes, one of which is students' cognitive abilities will be contributed to the prediction of learning outcomes in science [2].

At the end of each teaching and learning process, there is always an assessment. Academic assessment standard, preparing students for measuring their learning quality after the incentives learning [3]. Assessment of learning outcomes often using several instruments, such as multiple choice questions, true-false, and essay. Usually, multiple choice question has not been able to reveal the chemistry concepts in a comprehensive manner. The problem is, students are less to think constructively and tend to forget the basic chemistry concept they have learned before [4].

Based on the National Examination Result Data or daily test on several high schools collected, chemistry subjects are considered difficult for high school students. As a part of science, chemistry has 
a very complex subject. Therefore, it needs innovation in the learning evaluation at school[6]. In electrolyte and non-electrolyte material, on average students do not understand the concept of ionic compounds. This is caused because students do not understand the lessons in the previous semester on ionic bonding material. In addition, students also difficult in understanding the concepts of oxidation and reduction, especially in oxidation numbers, while these concepts are concepts that are interrelated with each other [14]. There are some of innovations that have been done in teaching learning process, such as application of several methods and approaches in learning activities. One of the approaches that can use is systemic approach. Systemic approach is a part of meaningfull learning. This approach is a set of several components that connected to each other by mutual relationship. All these components play a role in achieving a goal, with several charactheristics: integrating and concentrating on interaction between elements, and studying the effects of interaction [7]. In this study, the systemic approach used to develop the multiple choice questions, namely chemistry systemic multiple choices questions (CSMSQs). Based on the systemic approach in chemistry teaching and learning, multiple component will connect each other by a mutual relationship [8]. The alternatives of CSMCQs developed consist of three chemistry concepts that connected to each other.

\section{METHODS}

This research is a descriptive reasearch with quantitative approach. The population include 157 students $10^{\text {th }}$ grade, in one of senior high schools in Yogyakarta, Indonesia. All of the population used as a sample. The instrument used in this study is a 30 systemic multiple choice questions. The scope of subjects are electrolyte-nonelectrolyte and redox reaction. Bloom's devide the cognitive dimensions into $\mathrm{C}_{1}-\mathrm{C}_{6}$; remember, understanding, applying, analyzing, evaluating, and creating. For the $\mathrm{C}_{1}-\mathrm{C}_{3}$ can be categoryzed as a lower-order cognitive skills, while the $\mathrm{C}_{4}-\mathrm{C}_{6}$ as a high-order cognitive skills [10]. The questions of CSMCQs consisting of the $\mathrm{C}_{1}-\mathrm{C}_{6}$, because meaningful learning cognitive processes involve complex thought processes [10]. The instrument for data collection was developed by researcher. The distribution of questions are presented below.

Table 1. Distribution of Electrolyte-nonelectrolyte Subject Questions

\begin{tabular}{|c|c|c|c|c|c|}
\hline \multirow{2}{*}{ No } & \multirow{2}{*}{ Material } & \multicolumn{4}{|c|}{ Cognitive Dimension } \\
\hline & & $\mathbf{C}_{1}$ & $\mathbf{C}_{2}$ & $\mathrm{C}_{3}$ & $\mathrm{C}_{4}, \mathrm{C}_{5}, \mathrm{C}_{6}$ \\
\hline 1 & Definition of solution & & 1,2 & & \\
\hline 2 & Electrolyte-nonelectrolyte solution & 3 & & & 4,5 \\
\hline 3 & Ionic and covalent compounds & & & & 9,10 \\
\hline 4 & Strong and weak electrolyte & & 7,12 & & $6,8,11$ \\
\hline 5 & Ionizations degree & 14 & & & 13,15 \\
\hline 6 & Reduction-oxidation reacttions & & & & 16,17 \\
\hline 7 & Oxidation number concept & & 18 & 19 & \\
\hline 8 & Determination of oxidation number & & 28 & 20,22 & 26 \\
\hline 9 & Oxidation reaction & & & & 21 \\
\hline 10 & Reduction reaction & & & & 24 \\
\hline 11 & Oxidator reductor concept & & & & 23,25 \\
\hline 12 & Autoredoks reaction & & & & 27 \\
\hline 13 & Nomenclature in the concept of oxidation & & 29 & & 30 \\
\hline
\end{tabular}

Fifteen teacher from fourteen Senior High School in Yogyakarta, and five lecturer as expert judgement has reviewed the CSMCQs. Data obtained through an assessment questionnaire consisting of 20 
indicaors from 3 aspect. By using a scale of 5 proposed by Likert, an assessment score was obtained from the reviewer to determine the overall ideality percentage of the CSMCQs.

Table 2. The assessment result of CSMCQs on electrolyte-nonelectrolyte and redox reaction subject.

\begin{tabular}{lccc}
\hline \multirow{2}{*}{ Score } & \multicolumn{3}{c}{ Aspects } \\
\cline { 2 - 4 } & Structure of question & Chemistry concept & Construct \\
\hline \% Ideal & $90,66 \%$ & $88 \%$ & $88 \%$ \\
Category & Very good & Very good & Very good \\
\hline
\end{tabular}

The validity test of the research instrument was conducted on another 60 students of $10^{\text {th }}$ grade. The validity of the CSMCQs were analyzed using WINSTEPS software based on the RASCH model. The Rasch model is not dependent on the sample used [15]. Rasch measurements simultaneously sort structured questions from the hardest to the easiest and the respondents from the highest to the lowest. Therefore, the inconsistency of the answers from the respondents (misfit) or unusual patterns (outliers) will be detected [15].Items was valid should meet at least one of the criteria below [13].

- The value of Outfit Mean Square (MNSQ) between $0.5<\mathrm{MNSQ}<1.5$

- The value of Outfit Z-Standard (ZSTD) between $-2.0<$ ZSTD $<+2.0$

- The value of Point Measure Coorelation (Pt Mean Corr) between 0,4 $<\mathrm{Pt}$ Measure $<0,85$

The validity of the item can be seen from the Item (column) table: Fit Order. Validity test results are known as many as 30 items of Chemistry Systemic Multiple Choices Questions (CSMCQs) are valid. The validity results are:

- Items number 3, 15, and 29 are fit with the model because the ZSTD outfit values obtained in the range of -1.9 to 1.9 , which means that the data has a logical estimate, although the value of MNSQ outfit $\leq 0.5$ which means less productive for measurement but does not degrade the measurement quality [13].

- Item number 16 meets all three criteria, MNSQ 0.98 outfit value indicates good conditions for measurement, the value of outfit ZSTD - 0.2 states that the data has a logical estimate, and the value of Pt.Measure Corr 0.41. That is, the item fit with the model [13].

- The items other than those mentioned are still fit with the model although it only meets two criteria, namely MNSQ outfit value and ZSTD outfit value. Value Pt.Measure Corr obtained does not meet the criteria, ie $\leq 0.4$ but the items developed are still fit with the model [13].

Reliability test can be done by using Summary Statistics table in Winstep application. The reliability of the instrument is 0.95 , catogirized as very good criteria [13]. Then, to analyze the difficulty level of each item, must first know the value of person logit and logit items from all respondents [13]. Summary Statistics showing reliability of item can be known the average value of logit for person is 74.77 and the average value of logit for the item is 50.00. The difficulty level of the item can be known through the analysis of Variable Maps in Winstep application, the result shows below.

Table 3. The Difficulty Level of Questions

\begin{tabular}{cllc}
\hline No. & \multicolumn{1}{c}{ Criteria } & \multicolumn{1}{c}{ Question Number } & \multicolumn{1}{c}{ Percentage } \\
\hline 1 & Easy & $15,3,8,1,28,14,9,13,4,22,25,29,7,12,19,18,11,21,23$, & $66,67 \%$ \\
& & 10 & $23,22 \%$ \\
2 & Moderate & $2,24,20,30,27,16,5$ & $10 \%$ \\
3 & Difficult & $26,6,17$ & \\
\hline
\end{tabular}


In Indonesia, the answer option for Senir High School multilple choice questions consist of five. For CSMCQs, each options consist of 3 concept that students have been learned before, that related to the material being tested, such as: basic concept of solution, chemical reaction equation, chemical bonding etc. The data obtained was in the form of score.Moreover, the score gained was analyzed using percentage analysis. Thus, the equation used to count the percentage score from the data of the instrument was in the following:

Percentage $=\frac{\text { total score obtained }}{\text { maximum score }} \times \mathbf{1 0 0} \%$

The phases of data analysis were deciding the score of students' answer, counting the score of students' answer in each item, and determine the qualification criteria as follow.

Tabel 4. Qualification of cognitive ability criteria

\begin{tabular}{ccc}
\hline No. & Interval (\%) & Criteria \\
\hline 1 & $81-100$ & Very high \\
2 & $61-80$ & High \\
3 & $41-60$ & Middle \\
4 & $21-40$ & Low \\
5 & $\leq 20$ & Very low \\
\hline
\end{tabular}

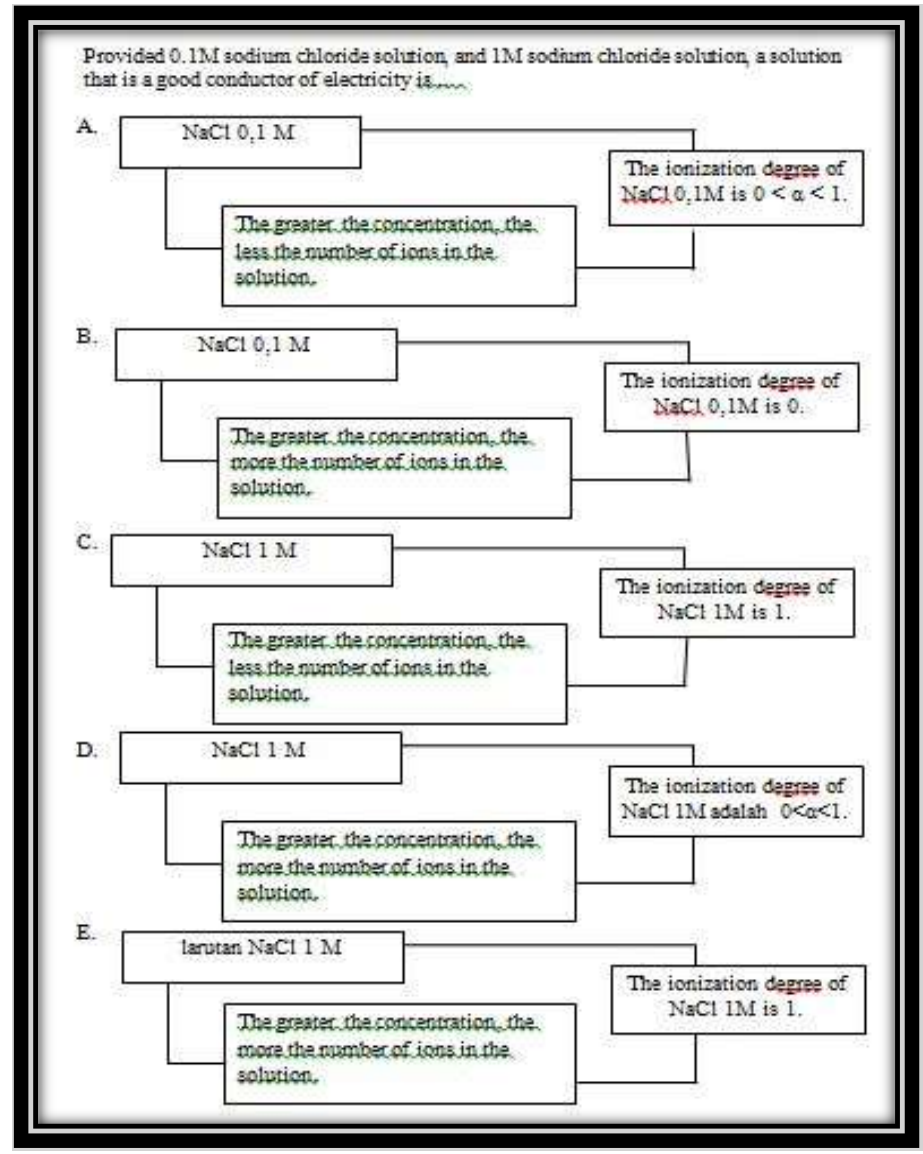

Figure 1. A part of CSMCQs on redox and electrolyte-nonelectrolyte solution 


\section{RESULTS AND DISCUSSION}

Questions are given to students after they have finished studying about the electrolyte-nonelectrolyte solution and redox reaction. Scores are given in is biserial scores: 1 for the correct answers and 0 for wrong answers. The results of the test, shown in Table 4.

Tabel 5. Frequency distribution of test scores

\begin{tabular}{cccc}
\hline No. & Interval & Frequency & Percentage \\
\hline 1 & $81-100$ & 96 & $61.15 \%$ \\
2 & $61-80$ & 59 & $37.58 \%$ \\
3 & $41-60$ & 2 & $1.27 \%$ \\
4 & $\leq 40$ & 0 & $0 \%$ \\
\hline & & 157 & $100 \%$ \\
\hline
\end{tabular}

Highest score obtained by the student is 100 , and the lowest score obtained by the student is 56. The average student test score is 83.54 . The test result scores were analyzed using descriptive percentage analysis. The results show that students have very high cognitive abilities. After knowing students' cognitive abilities, students' answer of each cognitive dimension $\mathrm{C}_{1}, \mathrm{C}_{2}, \mathrm{C}_{3}, \mathrm{C}_{4}, \mathrm{C}_{5}, \mathrm{C}_{6}$ were analyze. The result of percentage analysis for each cognitive dimensions is presented in the following figure.

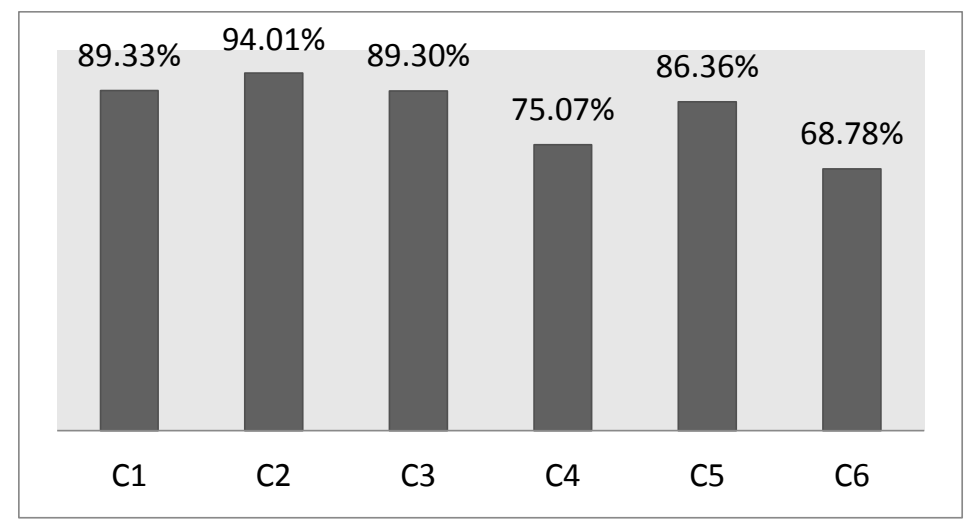

Figure 2. Percentage of student's correct answers in each cognitive level

1. At the level of cognitive dimension $\mathrm{C}_{1}$, students are required to recall the material they have learned before [10]. The results shows that $89.33 \%$ students, gave the correct answer for this level of cognitive dimension. This means that there are still $10.67 \%$ of students who answered incorrectly.

2. At the level of cognitive dimension $\mathrm{C}_{2}$, students are required to understand something after something is known and remembered. A student is said to understand something if he can determine the explanation of the question [10]. Understanding is a higher level of thinking ability than remembering. The results shows that $94.01 \%$ students, gave the correct answer for this level of cognitive dimension. This means that there are still $5.99 \%$ of students who answered incorrectly.

3. At the level of cognitive dimension $\mathrm{C}_{3}$, students are required to be able to apply common ideas, procedures, methods, principles, formulas, and theories learned in given situations [10]. The results shows that $89.30 \%$ students, gave the correct answer for this level of cognitive dimension. This means that there are still $10.7 \%$ of students who answered incorrectly. 
4. At the level of cognitive dimension $\mathrm{C}_{4}$, students are required to elaborate or describe a material or state according to smaller parts and be able to understand the relationship between the parts or factors that one with other factors [10]. The results shows that $75.07 \%$ students, gave the correct answer for this level of cognitive dimension. This means that there are still $24.93 \%$ of students who answered incorrectly.

5. At the level of cognitive dimension $\mathrm{C}_{5}$, students are required to integrate parts or elements logically, thus transforming into a scheme that is structured or develop a new scheme [10]. The results shows that $86.36 \%$ students, gave the correct answer for this level of cognitive dimension. This means that there are still $13.64 \%$ of students who answered incorrectly.

6. At the level of cognitive dimension $\mathrm{C}_{6}$, students are required to make judgments about a situation, value or idea, for example if student faced with several choices, they will be able to choose the best option, in accordance with the standards or criteria [10]. The results shows that $68.78 \%$ students, gave the correct answer for this level of cognitive dimension. This means that there are still $31.22 \%$ of students who answered incorrectly.

Based on the results, it is known that $\mathrm{C}_{1-5}$ cognitive level, students successfully answer correctly $>75 \%$. It can be said that the cognitive abilities of students are in the high category. These results is accordance with the principle of systemic learning that students able to conceptualize chemical conceptions as a prerequisite for the learning of electrolyte-nonelectrolyte solutions and redox reactions. The results of this study are related with the main objective of a systemic approach. The systemic approach helps students to build their thinking skills. Each component that students learn will work as a whole with a set of related components. Two of the result obtained from the systemic approaches that have been used were to generate meaningful learning for students, and to form students to develop the ability to connect the material they have just learned (basic concepts) to newly learned (more complex) concepts. Thus, students' cognitive ability structure is potentially formed and new information management processes can be easily regulated in complex concepts [11]. In addition, students can integrate what they have learned before, so they can be able to think systematically [10].

The question of $\mathrm{C}_{6}$ has the lowest percentage. It indicates that students are difficult to make judgments about a particular situation In addition, many students gave wrong answers on the determination of positive and negative poles, when given an electrolyte test scheme. It can caused by several characteristics of electrolyte-nonelectrolyte and redoks subject, such as needing some laboratory activity to conducting electrical current on various solutions, grouping the solution into an electrolyte solution and nonelectrolyte based on experimental data, then grouping electrolyte solution based on bond type [9]. This material is a subject that is considered abstract because the concept is obtained by counting activities and simple experiments, namely test one by one solution to be recorded and find out the end result. Various concepts related to electrolyte- nonelectrolyte solutions are taught with the aim to build students understanding about chemical concepts that related to electrolyte-nonelectrolyte materials, such as chemical solutions, and chemical bonds[9]. Therefore, it takes several ways to achieve students' thinking ability at various levels of cognitive dimension. It is necessary to involve students with various constructivist learning activities. Particular emphasis on certain material can be used as a foundation for students to connect the basic concept to more complex concepts, in this case related on electrolyte-nonelectrolyte solution and redox reaction [11]. 
The result of this research shows that the high cognitive abilities of students in the high-order cognitive $\left(\mathrm{C}_{4}, \mathrm{C}_{5}, \mathrm{C}_{6}\right)$ categories will automatically affected the cognitive abilities of lower-order cognitive $\left(\mathrm{C}_{1}, \mathrm{C}_{2}, \mathrm{C}_{3}\right)$ categories [10]. However, the relationship between the two is not always the same, there are several factors that influence the relationship of both such as learning process and approaches that used. Learning process that help students to think constructively can help students to relate the basic concept that they have before to a more complex concept. The opportunity to answer questions is exactly the same when students' abilities are compared with the difficulty level of the questions [13]. Other factor that influence the research results are is age of students' cognitive abilitiy theory. Learning process will follow the patterns and stage of developments according to age. The patterns and the stages are very hierarchical, certainly passed in a certain order. According to the theory of cognitive development, students in high school age have an abstractive thinking skills and hypoteses, so that students are able to think of something that may happen [12].

The results of this study will not always be the same if done at different research sites. The results of this study show students' cognitive abilities (in each cognitive dimension) are in the high category. Factors that influence the results of this study is the level of difficulty of the problems developed. Problems made are dominated by easy category questions. While the sample research used is students who come from high-school that have high grade-cognitive ability category (base on National Examination Result Data). If students have high cognitive abilities given easy category questions, then students will solve the problem quickly. Whereas, if research is conducted in low-grade schools, the results to be obtained will be different. Students with low cognitive abilities require a long time to complete the chemistry systemic multiple choices questions (CSMSQs). However, based on the student's review, CSMCQs electrolyte-nonelectrolyte solution subject can help to remind the chemistry concepts that have been studied before, making easier for student to understand the chemistry concepts, can stimulate their curiosity about the relationship of chemistry concepts [5].

\section{CONCLUSION}

The results of the CSMCQs analysis assessment by an expert judgment state that CSMCQs are appropriate and ideal for testing to students. The result of this study showed that students' who come from the high-grade school category have the high cognitive abilities on CSMCQs electrolytenonelectrolyte solution subject.

\section{REFERENCES}

[1] Boud, David. \& Falchikov, N. Rethinking assessment in higher educational: learning for the longer term. Routledge, 2007, 3.

[2] Lau, Shun. \& Roeser, R. W. Cognitive abilities and process in high school students' situational engagement and achievement in science. Routledge, 8(2), 139-162.

[3] Tikkanen, G. \& Aksela, M. Analysis of finnish chemistry matriculation examination questions according to cognitive complexity. Journals of uio, 2012, 8, (3), 258-286.

[4] Lagowski, J.J. SATL. Learning theory, and the physiology of learning. $20^{\text {th }}$ ICCE Proceeding, Mauritius, 2008, 3-8.

[5] Priyambodo, E \& Marfuatun. The development of systemic multiple choice questions (SMCQs) on redox and electrolyte-nonelectrolyte solution concepts in chemistry teaching and learning. Proceeding international seminar on mathematics, science, and computer science education, 2015, 92-95. 
[6] D Gabel. Improving teaching and learning through chemistry education research: a look to the future. The journal of strength \& conditioning research, 1999, 76(4), 548.

[7] Ivie, D.Stanley. Ausubel learning theory: an approach to teaching higher order thinking skills (education psychologist david paul ausubel). High school journal, 1998, 82(1), 35.

[8] Al-Basharieh, Zeid. Systemic approach effect on achievement of tafila school students in science. International journal of humanities and social science, 2011, 3(1), 46-52.

[9] Ghani, I. B., Ibrahim, N. H., Yahaya, N. A., \& Surif, J. Enhancing students' HOTS in laboratory educational activity by using concept map as an alternative assessment tool. Chemistry education research and practice, 2017, 18(4), 849-874.

[10] Anderson, W. Lorin \& Karthwohl, David, R. A taxonomy for learning, teaching, and assessing. New York, Longman, 2001.

[11] Fahmy, A. F. M., Lagowski, J. J. The use of a systemic approach in teaching and learning chemistry for the $21^{\text {th }}$ century. Journal Published by Pure Appl. Chem., 1999, 5(71), 859-863.

[12] Piaget, J. The psychology of intelligence. London, Routledge \& Paul, 1950.

[13] Sumintono, B and Widhiarso, W. Aplikasi model rasch untuk penelitian ilmu-ilmu sosial, Trimkom Publishing House, Bandung, 2013.

[14] Medina, P. Analisis miskonsepsi siswa kelas X pada materi larutan elektrolit nonelektrolit serta reaksi oksidasi dan reduksi dalam pembelajaran kimia di SMA N Kota Padang. Jurnal Pendidikan dan Teknologi Informasi, September 2015, 2(1), 6-8.

[15] Rasch, D., Kubinger, K. D., \& Yanagida, T. Using $R$ and SPSS. Chichester: John Wiley \& Sons, Ltd, 2011. 